This report was prepared as an account of work sponsored by an agency of the United States Governinent. Neither the United States Government nor any agency thereof, nor any of their employees, makes any warranty, express or implied, or assumes any legal liability or responsibility for the accuracy, completeness, or usefulness of any information, apparatus, product, or process disclosed, or represents that its use would not infringe privately owned rights. Reference therein to any specific commercial product, process, or service by trade name, trademark, manufacturer, or otherwise does not necessarily constitute or imply its endorsement, recommendation, or favoring by the United States Government or any agency thereof. The views and opinions of authors expressed herein do not necessarily state or reflect those of the United States Government or any agency thereof.

\title{
IMMOBILIZATION OF RADIOACTIVE STRONTIUM IN CONTAMINATED SOILS BY PHOSPHATE TREATMENT
}

\author{
K.H. KIM" ${ }^{1}$ S.Y. LEE, AND J.T. AMMONS ${ }^{1}$
}

ENVIRONMENTAL SCIENCES DIVISION

${ }^{1}$ The University of Tennessee, Knoxville, Tennessee.

For Proceedings of XIV International Symposium on the Scientific Basis for Nuclear Waste Management

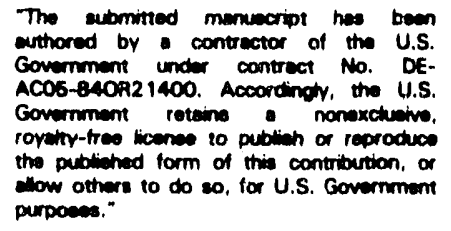


IMMOBILIZATION OF RADIOACTIVE STRONTIUM IN CONTAMINATED

SOILS BY PHOSPHATE TREATMENT

K. H. KIM*, S. Y. LEE"*, and J. T. AMMONS*

*The University of Tennessee, Department of Plant and Soil Science, Knoxville, TN 37901

** Oak Ridge National Laboratory, Environmental Sciences Division, Oak Ridge, TN 37831

\section{ABSTRACT}

The feasibility of in situ phosphate- and metal- (calcium, aluminum, and iron) solution treatment for $90 \mathrm{Sr}$ immobilization was investigated. Batch and column experiments were performed to find optimum conditions for coprecipitation of ${ }^{90} \mathrm{Sr}$ with $\mathrm{Ca}-, \mathrm{Al}$, and Fe-phosphate compounds in contaminated soils. Separate columns were packed with artificially ${ }^{85} \mathrm{~S} \mathrm{r}$ contaminated acid soil as weil as ${ }^{0} \mathrm{Sr}$-contarninated soil from the Oak Ridge Reservation. After metal-phosphate treatment, the columns were then leached successively with either tapwater or $0.001 \mathrm{M} \mathrm{CaCl}$ solution. Most of the ${ }^{85} \mathrm{Sr}$ coprecipitated with the metal phosphate compounds. Immobilization of ${ }^{85} \mathrm{Sr}$ and ${ }^{9} \mathrm{Sr}$ was affected by such factors as solution $\mathrm{pH}$, metal and phosphate concentration, metal-to-phosphate ratio, and soil characteristics. Equilibration time after treaiments also affected ${ }^{85} \mathrm{Sr}$ immobilization. Many technology aspects still need to be investigated before field applications are feasible, but these experiments indicate that phosphate-based in situ immobilization should prevent groundwater contamination and will be useful as a treatment technology for $90 \mathrm{Sr}$-contam- 
inated sites.

\section{INTRODUCTION}

Strontiurn-90 has been recognized as one of most abundant radionuclides in the contaminated areas at the Oak Ridge Reservation (ORR) and other U.S. Department of Energy facilities. The close chemical similarity of $\mathrm{Sr}$ to $\mathrm{Ca}$, which is common in soil and groundwater, allows $90 \mathrm{Sr}$ to be transported through food chains to man by plant uptake $[1,2]$. The frequent occurrence of ${ }^{0} \mathrm{Sr}$ in groundwater seeps around the disposal areas at Oak Ridge National Laboratory (ORNL) is evidence of its low adsorption and mobile nature in soils $[3,4,5,6]$. Strontium-90 has a relatively short half-life (28.9 years), but it has fairly high mobility under neutral to acidic soil conditions. Therefore, the environmental restoration program at ORNL. has supported the development and demonstration of in situ ${ }^{9} \mathrm{Sr}$. immobilization technologies.

Calcium, aluminum, and iron can form relatively insoluble phosphate compounds in the presence of phosphate anions. Precipitation and retention of the metal phosphate compounds are controlled by many chemical and physical factors, such as soil characteristics, metal and phosphate concentration, and solution pHs. Most of the well-developed soils in the ORR have acidic reactivity ( $\mathrm{pH} 6.5$ to 4.5 ) although they were developed from residua of dolostone or limestone. The treatment performance is directly related to the solubilities of the phosphate precipitates. The solubilities of the newly precipitated amorphous phosphate compounds are higher than crystalline phosphate compounds. However, the solubilities of the amorphous phosphate compounds are expected to be lower than other 
strontium compounds, such as carbonate, hydroxide, and exchangeable cationic forms of strontium.

The purpose of this investigation was to find a set of conditions for $9 \mathrm{~S}_{\mathrm{r}}$ immobilization in contaminated soils using phosphate-solution treatment with and without application of metal $(\mathrm{Ca}, \mathrm{Al}$, and $\mathrm{Fe})$ solutions.

\section{MATERIALS AND METHODS}

Two soils were selected for the $90 \mathrm{Sr}$-immobilization study, ${ }^{90} \mathrm{Sr}$ contaminated alkaline soil from Solid Waste Storage Area (SWSA) 5 (soil A) and uncontaminated acid soil from SWSA 6 (soil B) at ORNL. Bulk samples were air dried and sieved to $<2 \mathrm{~mm}$. Soil $A$ was mixed with sand to dilute the sample radioactivity and to increase hydraulic conductivity during the column studies. Soil A was used to test the effect of phosphate concentration and $\mathrm{pH}$. Soils $\mathrm{A}$ and $\mathrm{B}$ were used for testing the effect of soil, alkaline vs. acidic, equilibration time, and metal-phosphate treatments.

Soil columns were prepared using $2.54-\mathrm{cm}$-diam by $12.7-\mathrm{cm}$-long syringes. Glass wool was put into columns and $15 \mathrm{~g}$ of uncontaminated soil $B$ were added to the columns. Five grams of contaminated soil A or B were added on top of soil B. Two different chemical solutions were added to the columns. Ten milliliters of the first solution was added from the bottom by capillarity and $10 \mathrm{~mL}$ of the second solution from the top by pipetting to prevent soil pores from clogging with entrapped air bubbles. Phosphate solution was introduced from the bottom for aluminum- and iron-phosphate-systems. In contrast, the calcium solution was introduced from the bottom for calcium-phosphate-system. The columns were held in 
a mechanical vacuum extractor (Centurion International, Inc.) connected to syringes equipped with filter disks $(0.45 \mu)$ between soil columns and leachate-receiving syringes. A predetermined number of extractions were carried out with either $20 \mathrm{~mL}$ of tapwater or $20 \mathrm{~mL}$ of $0.001 \mathrm{M} \mathrm{CaCl}_{2}$ solution for each column.

Soil cation exchange capacity (CEC) was determined by sum of the cations at $\mathrm{pH} 7.0$ [7], organic matter by the Walkley-Black method [8], and soil $\mathrm{pH}$ using a combination $\mathrm{pH}$ electrode (1 to 2 , soil to water or $1 \underline{\mathrm{N} \mathrm{KCl}}$ solution ratio). The $\mathrm{pH}$ of leachates was also determined with a $\mathrm{pH}$ meter using a combination electrode (Radioneter Copenhagen pH M84 Research $\mathrm{pH}$ meter). Activity of $90 \mathrm{Sr}$ in each $5-\mathrm{mL}$ aliquot of leachates, contained in $20-\mathrm{mL}$ plastic scintillation vials, was determined by Cerenkov radiation counting using a liquid scintillation counter (Packard TRI-CARB Liquid Scintillation Spectrometer). Activity of ${ }^{85} \mathrm{Sr}$ was determined by counting with a lithium drifted germanium detector and a multichannel analyzer system (Nuclear Data, Ir. c., Model 6700). Counting times of 30 min and $5 \mathrm{~min}$ were employed for the ${ }^{9} \mathrm{Sr}$ and ${ }^{85} \mathrm{Sr}$ activity measurement. The time intervals were generally adequate to achieve a low-counting error. The activity of each leachate fraction was expressed as percent of the total activity applied to a soil column.

\section{RESULTS: AND DISCUSSION}

Two soils selected for this study were derived from the Maryville Formation of the Conasauga Group. Strontium-90-contaminated alkaline soil was from SWSA 5 (soil A) and uncontaminated acid soil was from SWSA 6 (soil B) at ORNL. Physical and chemical characteristics of the 
soils are given in Table I. Soil $\mathrm{A}$ had a higher $\mathrm{pH}, \mathrm{CEC}$, and organic matter content than soil B. Soil B had slightly higher clay content than soil A. The soil color indicated that the amount of iron oxide in soil $A$ was higher than that in soil $B$.

Effect of phosphate solution $\mathrm{pH}$

Twenty milliliters of phosphate solutions $(0.01 \mathrm{M}$ as phosphoric acid) buffered at $\mathrm{pH}$ values $6.0,7.0,8.0$, and 9.0 were added to soil $A$ to determine the effect of $\mathrm{pH}$ on ${ }^{0} \mathrm{Sr}$ leachability. The phosphate-treated soil columns were leached 14 times with $20 \mathrm{~mL}$ tapwater. The results of $90 \mathrm{Sr}$ activity leached from the phosphate-treated columns are presented in Fig. 1. The treatments of the phosphate solutions at all $\mathrm{pH}$ levels reduced the leachability of ${ }^{9} \mathrm{Sr}$ in comparison with the untreated control soil column. Soil columns treated with phosphate solution at higher $\mathrm{pH}$ had a lower 9 usr leachability. The phosphate-treated columns had a lower leaching rate, whereas the control had a higher leaching rate ir the beginning of the leaching. The cumulative ${ }^{9}{ }^{\circ} \mathrm{Sr}$ activity leached from the $\mathrm{pH} 9.0$ phosphate-treated column was less than $30 \%$ of the control after the second leaching. After the fourth leaching, the ${ }^{9} \mathrm{Sr}$ activities were similar among the leachates from soil columns treated with phosphate solutions of varying pHs.

A considerable enhancement of the $90 \mathrm{Sr}$ retention with elevated $\mathrm{pH}$ wals observed by Spalding [9] after alkali metal hydroxide treatments of ${ }^{9} 0 \mathrm{Sr}$ contaminated soils from low-level radioactive solid waste storage sites at ORNL. Several other reports also indicated that an increase in $\mathrm{pH}$ enhanced retention of strontium $[10,11,12]$, but there were substantially 
different opinions regarding both the magnitude and the optimum $\mathrm{pH}$ for enhancing strontium retention. Prout [11] found a maximum strontium retention at $\mathrm{pH} 7$ to 8 , whereas McHenry [10] and Rhodes [12] reported maxima at $\mathrm{pH} 10$ to 11.

A separate column experiment was performed to investigate the effect of the phosphate treatment on the immobilization of $85 \mathrm{Sr}$ at a high $\mathrm{pH}$. Twenty milliliters of a phosphate solution $\left(0.1 \mathrm{M}\right.$ as $\left.\mathrm{Na}_{3} \mathrm{PO}_{4}\right)$ at $\mathrm{pH}$ 11.5 was added to ${ }^{85} \mathrm{Sr}$ contaminated soil B. The phosphate-treated soil columns were leached eight times with $20 \mathrm{~mL}$ tapwater. The experiment showed that ${ }^{85} \mathrm{Sr}$ in the leachate was not detected even after eight consecutive leachings with tapwater. The treatment induced pore clogging through particle dispersion during the column studies. The tribasic sodiuin phosphate treatment was highly effective in reducing ${ }^{85} \mathrm{Sr}$ leachability through: (1) reduction of infiltration by clogging pores due to dispersion and (2) formation of ${ }^{85} \mathrm{Sr}$ phosphate compounds.

\section{Effect of solution concentration}

Five concentrations of phosphate solution $(0.1 \mathrm{M}, 0.05 \mathrm{M}, 0.01 \mathrm{M}$, $0.005 \mathrm{M}$, and $0.001 \mathrm{M}$ as phosphoric acid) adjusted to $\mathrm{pH} 9.0$ were used to test the effect of phosphate concentration on reducing ${ }^{0}{ }^{0} \mathrm{Sr}$ leachability using soil A. Twenty milliliters of the phosphate solutions were added to the columns, followed by 14 successive leachings with $20 \mathrm{~mL}$ of tapwater. The results showed that $90 \mathrm{Sr}$ leachability decreased with increasing phosphate solution concentration (Fig. 2). The amounts of strontium leached from 0.1 - $\mathrm{M}$-phosphate-treated columns were less than $6 \%$ of strontium leached from control columns after the second leaching. The 
effect of phosphate treatment diminished gradually as the leaching progressed, but even after the thirteenth leaching, the total strontium activity leached from 0.1-M-phosphate-treated columns was still only about $60 \%$ of the total activity leached from the control columns. Although the treatment effect gradually diminishes, the time required for this process to occur, even under humid soil conditions, will allow for a substantial radioactive decay of the $90 \mathrm{Sr}$. No further experimentation was conducted to determine an optimum phosphate concentration above $0.1 \mathrm{M}$ because experimental data on ${ }^{90} \mathrm{Sr}$ fixation with a phosphate concentration above 0.1 $M$ would not likely be used in most practical applications, except perhaps in small point spills.

\section{Effect of ohosphate to metal ratio}

To find an optimum volume ratio of phosphate to metal solution for maximum ${ }^{85} \mathrm{Sr}$ removal, tive phosphate-metal solutions were prepared with phosphate-to-metal ratios of $5: 1,2: 1,1: 1,1: 2$, and $1: 5$ (40 $\mathrm{mL}$ total volume) using $0.1 \mathrm{M}$ tribasic sodiurn phosphate and metal chloride solutions in the presence of $3 \mathrm{~g}$ soil B. Strontium- 85 solution was added to the metal solutions, followed by mixing of the phosphate and metal solutions to proper volume ratios, and then $\mathrm{pHs}$ were adjusted to around 9.0. After $24 \mathrm{~h}$ equilibration, centrifugation and filtration, the filtrates were analyzed for ${ }^{85} \mathrm{Sr}$. At a phosphate-to-metal ratio of $5: 1$, the amount of ${ }^{85} \mathrm{Sr}$ removed from solution was $52.4 \%$ for aluminum-phosphate and $98.0 \%$ for iron-phosphate. At a $1: 1$ ratio, the amount of removed ${ }^{85} \mathrm{Sr}$ reached a maximum of $99.8 \%$ for both treatments, but at a $1: 5$ ratio the amount of ${ }^{85} \mathrm{Sr}$ removed was $63.9 \%$ for aluminum-phosphate and $79.8 \%$ for iron-phos- 
phate. The percentage of $85 \mathrm{Sr}$ removed from solution with iron-phosphate treatment was higher than that with aluminum-phosphate treatment through all the ratios, with the $1: 1$ ratio the most effective for either treatment.

\section{Effect of equilibration time after metal-phosphate treatment}

Four sets of soil columns were prepared to examine the effect of equilibration time after metal-phosphate treatments on reducing $85 \mathrm{Sr}$ leachabilities using artificially ${ }^{85} \mathrm{Sr}$ contaminated soll B. One day, $3 \mathrm{~d}, 5$ $d$, and $7 \mathrm{~d}$ after treatment, solutions were extracted followed by eight successive leachings with $0.001 \mathrm{M} \mathrm{CaCl}_{2}$ solution. More ${ }^{85} \mathrm{Sr}$ was immobilized with increasing equilibration time for all three systems, but no trend was evident for the control. Most of the ${ }^{85} \mathrm{Sr}$ was immobilized in the aluminum-phosphate and iron-phosphate systems after $7 \mathrm{~d}$ of equilibration. In contrast, the calcium-phosphate system maintained a relatively high level of mobile $85 \mathrm{Sr}$ compared to the aluminum-phosphate and iron-phosphate systems. The ${ }^{85} \mathrm{Sr}$ leachability after a 7-d-equilibration period was reduced to $61 \%, 6 \%$, and $15 \%$ of that after 1 -d-equilibration for calcium-phosphate, aluminum-phosphate, and iron-phosphate systems, respectively.

The initial stages of the reaction products of metal-phosphate treatments are metastable, but they will become more stable and less soluble phosphate compounds with time. Lindsay and Moreno [13] developed a unified solubility diagram of soils that included phosphate compounds of $\mathrm{Ca}, \mathrm{Al}$, and $\mathrm{Fe}$. In alkaline soils, calcium phosphates are the most stable minerals. They decrease in solubility in the order 
CaHPO $4 \cdot 2 \mathrm{H}_{2} \mathrm{O}$ (brushite) $>\mathrm{CaHPO}_{4}$ (monetite) $>\mathrm{Ca}_{8} \mathrm{H}_{2}\left(\mathrm{PO}_{4}\right) \cdot 5 \mathrm{H}_{2} \mathrm{O}$ (octocalcium phosphate) $>\beta-\mathrm{Ca}_{3}\left(\mathrm{PO}_{4}\right)_{2}$ ( $\beta$-tricalcium phosphate) $>\mathrm{Ca} \mathrm{a}_{5} \mathrm{OH}\left(\mathrm{PO}_{4}\right)_{3}$ (hydroxyapatite) $>\mathrm{Ca}_{5} \mathrm{~F}\left(\mathrm{PO}_{4}\right)_{3}$ (fluorapatite). In a greenhouse experiment, Lehr and Brown [14] observed that $\mathrm{CaHPO}_{4} \cdot 2 \mathrm{H}_{2} \mathrm{O}$ changed to $\mathrm{Ca}_{8} \mathrm{H}_{2}\left(\mathrm{PO}_{4}\right)_{6}$ and colloidal apatite in caicareous soils. In acid solls, $\mathrm{AlPO}_{4} \cdot 2 \mathrm{H}_{2} \mathrm{O}$ (variscite) is shown to be the stable mineral, followed by $\mathrm{FePO}_{4} \cdot 2 \mathrm{H}_{2} \mathrm{O}$ (strengite), $\mathrm{H}_{6} \mathrm{~K}_{3} \mathrm{~A} \mathrm{I}_{5}\left(\mathrm{PO}_{4}\right)_{8} \cdot 18 \mathrm{H}_{2} \mathrm{O}$ (potassium taranakite), and then $\mathrm{H}_{6}\left(\mathrm{NH}_{4}\right)_{3} \mathrm{~A} \mathrm{I}_{5}\left(\mathrm{PO}_{4}\right)_{8} \cdot 18 \mathrm{H}_{2} \mathrm{O}$ (ammonium taranakite). The initial reaction products such as the taranakites and amorphous $\mathrm{Fe}$ and $\mathrm{Al}$ phosphates in acid soil are thought to change with time to variscite-like and strengitelike crystalline compounds. In an incubation experiment, Taylor et al. [15] found that $\mathrm{Fe}_{3} \mathrm{KH}_{8}\left(\mathrm{PO}_{4}\right)_{6} \cdot 6 \mathrm{H}_{2} \mathrm{O}$ and $\mathrm{CaFe}_{2} \mathrm{H}_{4}\left(\mathrm{PO}_{4}\right)_{4} \cdot 5 \mathrm{H}_{2} \mathrm{O}$ changed to strengite residues.

Precipitates of metal-phosphate prepared separately were analyzed by $X$-ray diffractometry. The diffraction pattern of the calclum-phosphate precipitate was matched to calcium orthophosphate hydrate $\left(\mathrm{Ca}_{3}\left(\mathrm{PO}_{4}\right)_{2} \cdot \mathrm{nH}_{2} \mathrm{O}\right)$. However, the peaks of the precipitate were relatively weak and broad. The diffraction patterns of the aluminum- and iron-phosphate showed no evidence for any crystalline species.

Although the equilibration time used for our experiment ( $\max 7 \mathrm{~d}$ ) may not be long enough compared to those used by others [14, 15], it is natural to assume that, with time, some portion of the amorphous metalphosphates will change to a more stable crystalline phosphate mineral, depending on soil chemical environments.

\section{Effect of soil characteristics}


An experiment was carried out to test the effect of soil acidity on reducing ${ }^{85} \mathrm{Sr}$ leachability. Artificlally ${ }^{85} \mathrm{Sr}$-contaminated alkallne soll (soll A) and acid soil (soil B) were packed into columns. After metalphosphate treatments, columns were leached eight successive times with $20 \mathrm{~mL}$ of $0.001 \mathrm{M} \mathrm{CaCl}_{2}$ solution. The results of the experiment are presented in Fig. 3.

The phosphate-aluminum and -iron treatments reduced $85 \mathrm{Sr}$ leachabilities noticeably for both soils. For soil $A$, the cumulative percentages of ${ }^{85} \mathrm{Sr}$ removed after eight leachings for phosphate-aluminum and phosphate-iron were $21 \%$ and $28 \%$ of that of the control, respectively. Although ${ }^{85} \mathrm{Sr}$ was leached gradually from the phosphate-aluminum and phosphate-iron treatments of soil $\mathrm{B}$, the cumulative percentages of ${ }^{85} \mathrm{Sr}$ leached after eight leachings were only $1 \%$ and $2 \%$ for the phosphate-aluminum and phosphate-iron treatments, respectively. The calcium-phosphate treatment of soil $\mathrm{A}$ exhibited a noticeable decrease in ${ }^{85} \mathrm{Sr}$ leachabillties compared to the control, whereas more ${ }^{85} \mathrm{Sr}$ was leached from soll $B$ than from the control. The observed higher ${ }^{85} \mathrm{Sr}$ leaching of soil B than with the control resulted from the fact that $85 \mathrm{Sr}$ and $\mathrm{Ca}$ could not precipitate as phosphate compounds because of soil acidity, but rather competed with each other for retention sites in the soil.

\section{CONCLUSION}

$\mathrm{An}$ in situ phosphate- and metal- $(\mathrm{Ca}, \mathrm{Al}$, and $\mathrm{Fe})$ solution treatment was selected for a feasibility study as a potential technology for ${ }^{90} \mathrm{Sr}$ immobilization in an alkaline soil (soil A) and an acid soil (soil B). Both batch and column experiments were performed to find optimum conditions 
for phosphate treatment and for coprecipitation of $90 \mathrm{Sr}$ with $\mathrm{Ca}, \mathrm{Al}$, and Fe as phosphate compounds in contaminated solls. The following information has been obtained from the laboratory experiments:

1. The phosphate treatments at all $\mathrm{pH}$ levels (6 to 9) reduced the leachability of $90 \mathrm{Sr}$, with the higher $\mathrm{pH}$ treatment resulting in lower leachability. The tribasic sodium phosphate treatment at a very high $\mathrm{pH}$ (11.5) appears to have good potential as a simple and effective means for reducing ${ }^{85} \mathrm{Sr}$ leachability.

2. The ${ }^{85} \mathrm{Sr}$ leachability decreased with increasing phosphate concentration from $0.01 \mathrm{M}$ to $0.1 \mathrm{M}$.

3. In a batch experiment, the optimum molar ratio of phosphate to metal was 1 to 1 .

4. Immobilization of $85 \mathrm{Sr}$ grew with increasing equilibration time after metal-phosphate treatments.

5. The phosphate-aluminum and -iron treatments reduced ${ }^{85} \mathrm{Sr}$ leachabilities noticeably for both soil $A$ and $B$. For soil $A$, the calcium-phosphatetreatment showed a noticeable decrease in $85 \mathrm{Sr}$ leachabilities compared to the control, whereas the calcium-phosphate treatment leached more ${ }^{85} \mathrm{Sr}$ than the control for soil B.

Despite many detailed technology aspects which need to be investigated before a field demonstration, the laboratory results indicate that a phosphate-based in situ treatment would be an attractive option for sites contaminated mainly by $90 \mathrm{Sr}$. The in situ containment of $90 \mathrm{Sr}$ would prevent groundwater contamination and lead to eventual decommissioning of the sites through decay of the radionuclides. 
T'ins researcin was sponsored by the Office of Defense Waste and Transportation Management, U.S. Department of Energy, under contract DEAC05-84OR21400 with Martin Marietta Energy Systems, Inc., and by the Departmer:: of Plant and Soil Science, The University of Tennessee, Knoxville. Publication No. 0000, Environmental Sciences Division, Oak Ridge National Laboratory.

\section{REFERENCES}

1. S. W. Francis, TID-27564, National Technical Information Service, Springfield, Virginia (1978).

2. W. Stumm and J. J. Morgan, Aquatic Chemistry. An Introduction Emphasizing Chemical Equilibria in Natural Waters. John Wiley \& Sons, Inc., New York. p. 83-84. (1970).

3. H. S. Arora, T. Tamura, and W. J. Boegly, ORNL/TM-7138, Oak Ridge National Laboratory, Oak Ridge, Tennessee (1980).

4. J. O. Duguid, ORNL-5017, Oak Ridge National Laboratory, Oak Ridge, Tennessee (1975).

5. D. D. Huff, N. D. Farrow, and J. R. Jones, Environ. Geol. 4, 53 (1982).

6. L. A. Melroy, D. D. Huff, and N. D. Farrow, ORNLTM-10043, Oak Ridge National Laboratory, Oak Ridge, Tennessee (1986).

7. G. W. Thomas, Exchangeable Cations. Irr A. L. Page (ed.) Methods of Soil Analysis. Part 2. 2nd ed. Agronomy 2, 159 (1982).

8. D. W. Nelson and L. E. Sommers, Total Carbon, Organic Carbon, and Organic Matier. In A. L. Page (ed.) Methods of Soil Analysis Part 2. 2nd ed., Agronomy 2,539 (1982).

9. B. P. Spalding, Soil Sci. Soc. Am J. 44, 703 (1980).

10. J. R. McHenry, Scil Sci. Soc. Am. Pron. 22, 514 (1958). 
11. W. E. Prout, Soil Sci. 86, 13 (1958).

12. D. W. Rhodes, Soil Sci. Soc. Am. Proc. 21, 389 (1957).

13. W. L. Lindsay and E. C. Moreno, Soil Sci. Soc. Am. Proc. 24, 177 (1960).

14. J. R. Lehr and W. E. Brown, Soil Sci. Soc. Am. Proc. 22, 29 (1958).

15. A. W. Taylor, E. L. Gurney, and J. R. Lehr, Soil Sci. Soc. Am. Proc. 27, 145 (1963). 


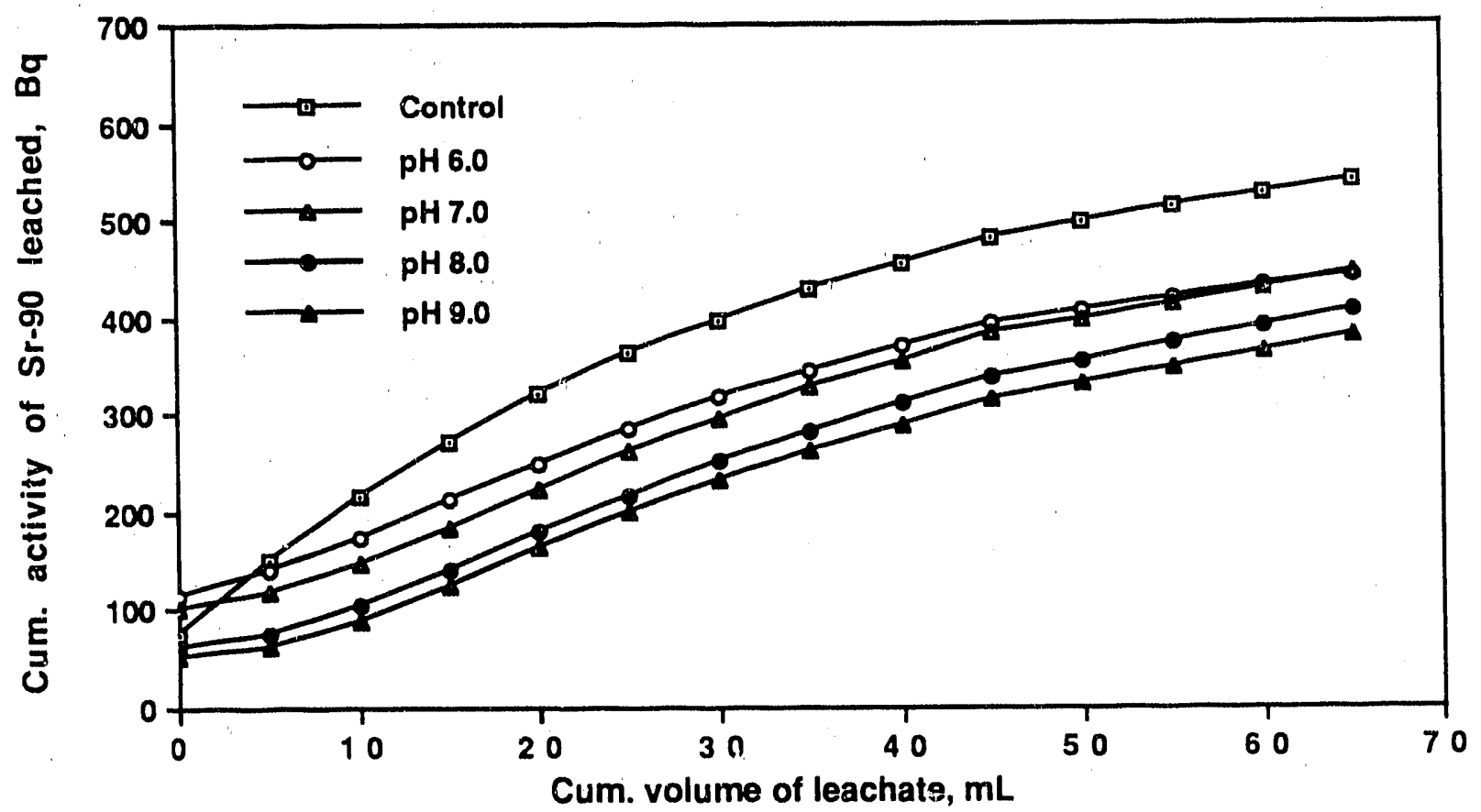

Fig. 1. Effect of phosphate solution pH on Sr-90 leachability with soil A.

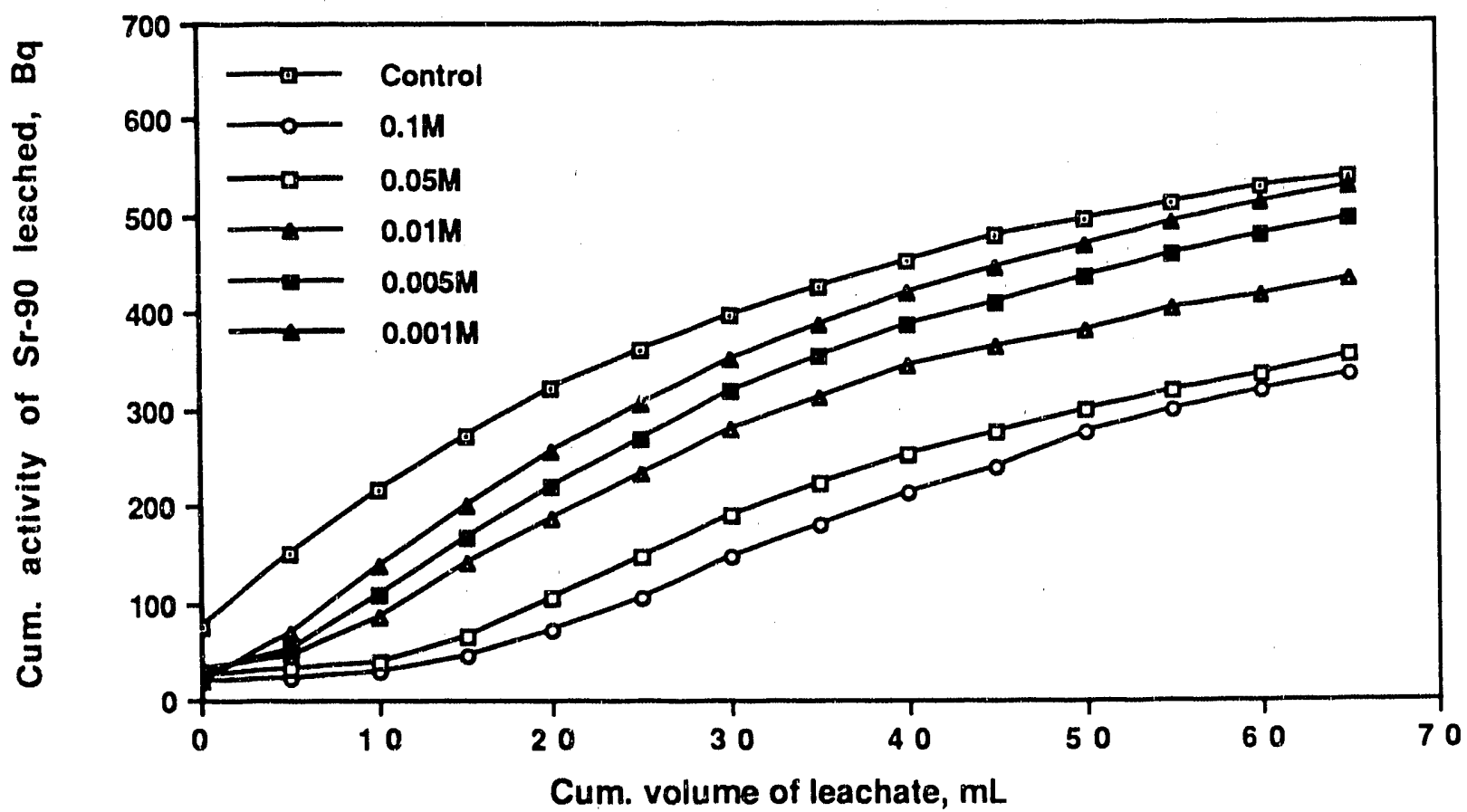

Fig. 2. Effect of phosphate solution concentration on Sr-90 leachability with soil $A$. 

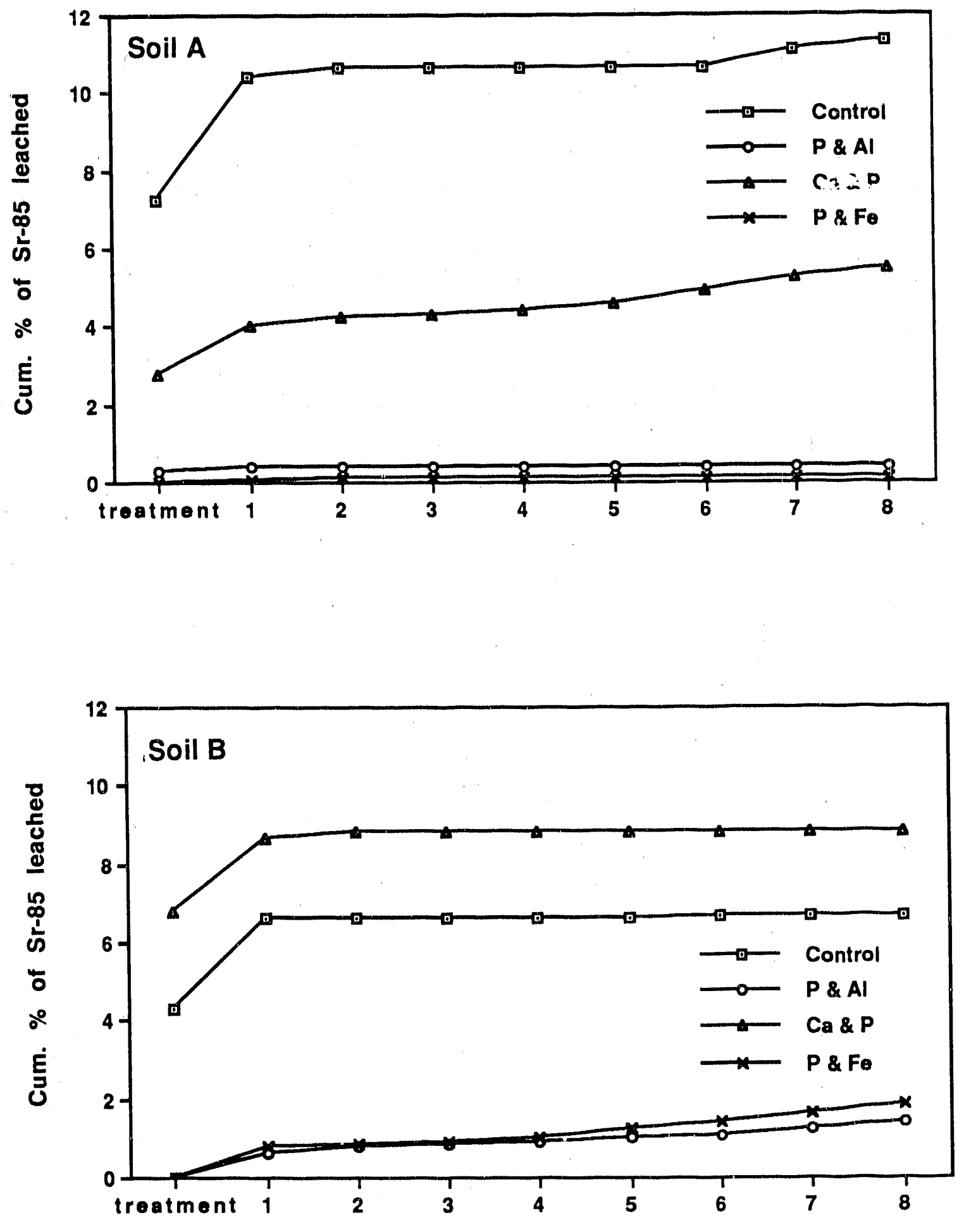

No. of leaching

Fig. 3. Effect of soil characteristics (soil A and soil B) on Sr-85 leachability after metal-phosphate treatments. 
Table I. Characteristics of soil samples used for the experiments

\begin{tabular}{cccccccccc}
\hline Soil & Color & pHwater & pHKCl & Sand & Silt & Clay & CEC & Sr-90 & O.M.a \\
\hline & & & & $\ldots$ & $-\%$ & $\ldots$ & $\mathrm{mg} / 100 \mathrm{~g}$ & $\mathrm{~Bq} / \mathrm{g}$ & $\%$ \\
$\mathrm{~A}$ & LB $^{\mathrm{b}}$ & 8.47 & 7.84 & 40 & 28 & 32 & 22.7 & 2258 & 4.1 \\
B & RBC & 5.40 & 3.81 & 28 & 35 & 37 & 11.0 & n.d. & 0.3 \\
\hline
\end{tabular}

aOrganic matter content.

bLight brown.

cReddish brown. 

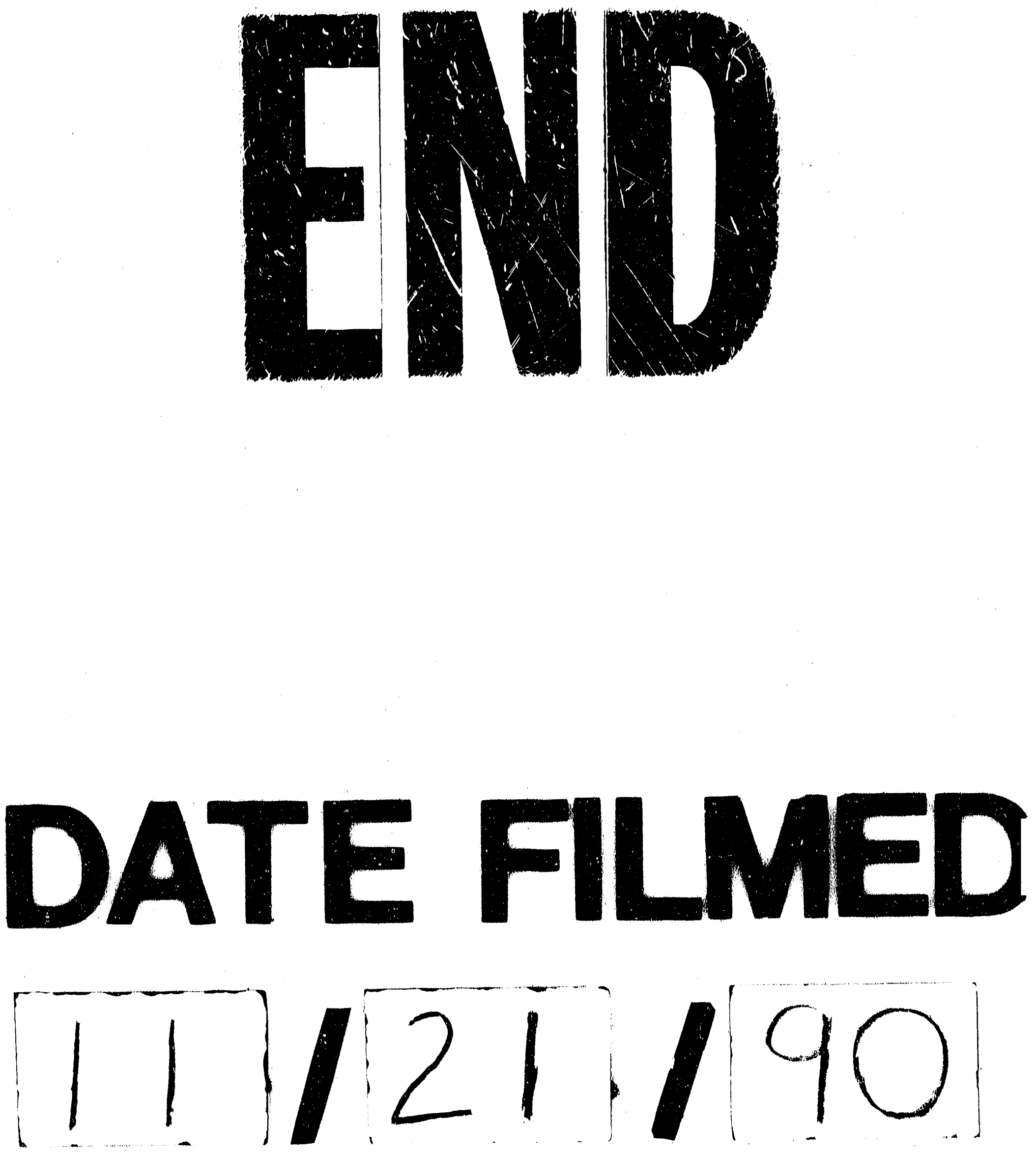
